\title{
Design of Competitiveness Index Software of Food Small Medium Enterprises (SMEs) With Diamond Porter Model Adaptation
}

\author{
Ryan Ardianto1, Roni Kastaman², Irfan Ardiansah', Totok Pujianto² \\ 1Alumnae Department of Agricultural Engineering and Bio system \\ Faculty of Agroindustrial Technology Padjadjaran University \\ ${ }^{2}$ Lecturer at Department of Agroindustrial Technology, \\ Faculty of Agroindustrial Technology Padjadjaran University \\ Email: snaip2011@gmail.com
}

\begin{abstract}
Small Medium Enterprises (SME) in food was contributed 13,15\% on Gross Domestic Product (GDP) 2013. However, SMEs in food had the problems in the management organization that could affect the product competitiveness. The local SMEs in food is less competitive compared with the similar foreign overseas product. In order to anticipate the negative impact of the broader market, the competitiveness measurement was needed to be conducted on understanding the strength of SMEs in food. Competitive measurement can be done by creating web application to reduce measuring process. This research using Designing methods (system engineering) using diamond porter model as competitiveness measurement method of SME in foods. Web application functioned as SME in foods grading, competitiveness weighing, SME in foods index measurements and City SMEs index measurements. Index value that were yielded grouped into three categories which were high, medium, and low. There was a color indicator on index value display that functioned to classifying competitiveness index value. ID was needed to access this web application, those things intended to guard the safety of data contained in this web application.
\end{abstract}

Keyword: SME in foods, competitiveness, web application

\section{INTRODUCTION}

Recently, the development of industry in Indonesia have increased. The developing process are supported by the government through the business permit [4]. This growth has a positive point in overcoming national problems such as high unemployment and poverty or slow export growth. The economic development is dependent to the industrial sectors, due to it has a huge contribution for a national economy [5].

Industrial sector has a great portion to absorb the number of employee. Particularly SME which have a bigger contribution in employment than the large scale industry due to it does not require certain educational qualifications in running its activities (Kusbiantono in [1]). SME also contributes to
Gross Domestic Product (GDP) which in 2012 contributed $10 \%$ of total GDP.

The government urged the SME's actor to increase their competitiveness in facing the global market. The SME also targeted by the government to be contributed around $50 \%$ of GDP by 2025 (Hidayat in [1]). In other hand, SME still faced the problems such as lack of technological expertise and low marketing. It directly affects the competitiveness of SME's product. Another problem faced by SME is AEC (ASEAN Economic Community). Ministry of Industry explained that Facing AEC, SME is still considered vulnerable due to the low competitiveness of SME's product. It insinuated that foreign product will be mastering the global market competitiveness.

Following the issues, it is essential to conduct the measurement of SME's 
competitiveness to explore the weak points of it. Measurement of SME's competitiveness is expected to improve the weak points of SME followed by several action from the government and SME's actor. The outcome of this research was addressing the deficiencies of SME to face the AEC through enhancing regional competitiveness.

Competitiveness is the ability of an industry to gain the competitive advantage [2]. The Increased od SME's competitiveness can be seen after the process of competitiveness measurement by determining the value of the combined index of SME's supporting factors. According to Porter [2], there are four dimensions affecting the competitiveness of industries, as follow: (1) condition factor; (2) conditions of demand; (3) corporate strategy and competition structure; and (4) supporting industries and related industries.

Porter combines these four dimensions into a model known as the Diamond Porter Model. The four major dimensions in the Diamond Porter Model are interconnected where in each dimension there are several things that determine the value of that dimension [2].

Besides the four main dimensions, there are still two supporting dimensions that can affect the competitiveness of industry, which is government and opportunity.

Measurements of competitiveness in SME will be conducted by using Diamond Porter Model. The Diamond Porter model is very suitable for measuring the competitiveness of SME and referring to the widely use of this model in research on competitiveness. Wiyadi [5], on Measurement of SME Competitiveness Index in Central Java takes a long time and complicated calculation in weighting factors that influence the competitiveness and the calculation of competitiveness index. The measurements of the competitiveness of SMEs currently still has problems on the measuring instruments and measuring mechanisms used in the process.

To facilitate the measurement of SME competitiveness it is necessary to design the software. This takes into consideration the rapidly expanding use of technology.
Internet was one of technology that experienced rapid development along with the development of existing programs in computers and smartphones. Web application is form of software that will be designed in this study along with current technology condition. By designing the software in the form of web applications is able to accelerate the process of entry of data from field measurements directly to the server, so that the data stored directly in the database and to make the overall measurement only needed to retrieve data from the one that already stored in the server. With the design of this software to measure the competitiveness in SME in food is able to become a measuring tool and could ease the mechanism in measuring the competitiveness in SME in food.

\section{METHODOLOGY}

The method used in this research is engineering method which is designing and making program. Programming languages used in this include HTML, SQL, PHP and JavaScript. The system divides the value of competitiveness index into 6 dimensions, there are conditions of demand, condition factors, competition structure and corporate strategy, supporting industries, government and opportunity.

The steps of this research is divided into several stages, as follow as:

\section{a. Study of Literature}

This process to be conducted to conclude the variables and indicators that are used in every dimensions in Porter. The results of this process are the variables and indicators that referred to the Table 1.

Table 1. Hierarchy SME in food Competitiveness

\section{Condition Factors dimension}

A. Resources.

B. Infrastructure

i. Electrical condition

ii. Water condition

C. Labor.

i. Average education

ii. Knowledge

D. Technology

2. Condition of demands dimension

A. Access to market 
B. Market growth

C. Market segment

3. Competition structure and company strategies dimension

A. Managerial Ability

i. Work Hour distribution

ii. The structure of company

B. Competitive Strategy

i. Product standardization

ii. Product Innovation

iii. Promotion Intensity

C. Newcomer threats

i. Access to materials

ii. Government permission

4. Supporting Industries / related industries dimension

A. Material Suppliers

i. Cooperation

ii. Industry location

B. Distributors

i. Cooperation

ii. Industry location

C. Promotion media

D. Financial institutions

E. Retail

5. Governmental dimension

6. Dimension of Opportunity

A. Climates

B. Festival

\section{b. Assessment of SME in food}

The assessment of SME in food conducted by interviewing the industry players. The assessment consists from one to five. The value of one signifies the lowest condition for the competitiveness in the SME in food and the value of five signifies the highest condition for the competitiveness in SME in food.

\section{c. Weighting of Competitiveness}

The weighting of the competitiveness in SMEis done by using Analytical Hierarchy Process (AHP) formula. Weighting is completed by comparing the elements of competitiveness that have the same level.

The weighting was conducted by using AHP principle which is pairing comparison. Dimensions weighting conducted by comparing between dimensions, variables and indicators. Variables which used in weighting is variables within the same dimensions. The use of indicators is similar to the weighted variables, the indicators used should be in the same variable. The results of pairing comparisons are in the form of a matrix like the Table 2 .

Table 2. Matrices Comparison

\begin{tabular}{ccccc}
\hline & A & B & C & D \\
\hline A & A / A & B / A & C / A & D / A \\
\hline B & $\mathrm{A} / \mathrm{B}$ & $\mathrm{B} / \mathrm{B}$ & $\mathrm{C} / \mathrm{B}$ & $\mathrm{D} / \mathrm{B}$ \\
\hline $\mathbf{C}$ & $\mathrm{A} / \mathrm{C}$ & $\mathrm{B} / \mathrm{C}$ & $\mathrm{C} / \mathrm{C}$ & $\mathrm{D} / \mathrm{C}$ \\
\hline $\mathrm{D}$ & $\mathrm{A} / \mathrm{D}$ & $\mathrm{B} / \mathrm{D}$ & $\mathrm{C} / \mathrm{D}$ & $\mathrm{D} / \mathrm{D}$ \\
\hline
\end{tabular}

where:

A / B / C / D = Dimension/ variable/ indicator of competitiveness.

Value that is used in weighting ranges from one to nine [3], with definitions like the table below:

Table 3. Weighting Value

\begin{tabular}{cl}
\hline Value & \multicolumn{1}{c}{ Information } \\
\hline 1 & $\mathrm{X}$ is just as important as $\mathrm{Y}$ \\
\hline 3 & $\mathrm{X}$ is slightly more important than $\mathrm{Y}$ \\
\hline 5 & $\mathrm{X}$ is clearly more important than $\mathrm{Y}$ \\
\hline 7 & $\mathrm{X}$ is clearly more important than $\mathrm{Y}$ \\
\hline 9 & $\mathrm{X}$ is absolutely more important than $\mathrm{Y}$ \\
\hline
\end{tabular}

The pairing comparison matrix is processed to obtain an eigenvector. The steps used to find the eigenvector value are:

- Squares matrices of pairwise results.

- Increase the value of each row where the first row represents the value of the dimension / variable / indicator on the same row. So is the value on the next line.

- Normalize the number of values of each row by dividing the number of row values on that row by the total number of values.

After obtaining the eigenvector of each line, the next step is to determine the average value of the consistency vector. The formula used to obtain the value of consistency vector:

$$
p=\text { comparation matrices } \times \text { eigenvector }
$$

where:

$\mathrm{p}=$ consistency vector value 
After obtaining the eigenvector of each row, the next step is to determine the value of consistency index (CI). The value of CI is intended to know the consistency of the weighting done by the respondents. The formula is as follows:

$$
C I=\frac{p-n}{n-1}
$$

where:

$\mathrm{CI}=$ consistency index

$\mathrm{p}=$ average value of consistency vector

$\mathrm{n}=$ total data

The last step is to find the value of consistency ratio (CR), it takes random index value (RI) to get $C R$ value. The value of RI depends on the value of $n$ used. The list of RI values is listed in the table issued by Oakridge Laboratory as below:

Table 4. Random Index Value (RI)

\begin{tabular}{cc}
\hline $\mathbf{n}$ & $\mathbf{R I}$ \\
\hline 1 & 0.00 \\
\hline 2 & 0.00 \\
\hline 3 & 0.58 \\
\hline 4 & 0.9 \\
\hline 5 & 1.12 \\
\hline 6 & 1.24 \\
7 & 1.32 \\
\hline 8 & 1.41 \\
\hline 9 & 1.45 \\
\hline
\end{tabular}

The value of RI is adjusted to the table values listed above. The formula used to find the value of CR is:

$$
C R=\frac{C I}{R I}
$$

where:

$$
\begin{aligned}
& \mathrm{CR}=\text { Consistency ratio value } \\
& \mathrm{CI}=\text { Consistency index value } \\
& \mathrm{RI}=\text { Random index value }
\end{aligned}
$$

The weighting is considered consistent if the value of $C R \leq 0.1$, if the value of CR is not in accordance with the provisions then the weighting is declared inconsistent.

\section{d. Index Measurement of Competitiveness}

The competitiveness value index of a SME in food is obtained by using the value data concerned and the weight value that has been filled by the respondent. The calculation of the index value is divided into three levels: the indicator index, the index variable and the dimension index.

Indicator indexes can be obtained by using data of SME in food assessment directly. The formula used to find the indicator index value of SME that is:

$\operatorname{Indeks}\left(X_{i j k}\right)=\frac{X_{i j k}-X_{\min }}{X_{\max }-X_{\min }}$

where:

$\mathrm{X}_{\mathrm{ijk}}=$ Index indicators value of competitiveness in SME as I dimension, $\mathrm{J}$ variable, and $\mathrm{K}$ indicator

$X_{\min }=$ Lowest value from indicator $X_{\mathrm{ijk}}$.

$X_{\max }=$ Highest value from indicator $X_{i \mathrm{ijk}}$.

The variable index of SME is obtained by multiplying the value of the indicator index by the indicator's weighted value. The formula used is:

$$
I\left(V_{i j}\right)=\sum_{k=1}^{n} P_{i j k} . I\left(X_{i j k}\right) \ldots \ldots \ldots
$$

where:

$I\left(V_{i j)}=\right.$ Value index of $j$ variable, I dimension.

$\mathrm{P}_{\mathrm{ijk}}=$ The weight value of the AHP of the $\mathrm{k}$ indicator, the j-variable, the i-dimension.

$\mathrm{X}_{\mathrm{ijk}}=$ Indicator value of the $\mathrm{i}$-dimension, $\mathrm{j}$ variable and k-indicator.

The dimension index of a SME in food is obtained by multiplying the value of the variable index by the weighted value of that variable. The formula used is:

$$
I\left(D_{i}\right)=\sum_{j=1}^{n} P_{i j} . I\left(V_{i j}\right) \ldots \ldots \ldots
$$

where:

$I\left(D_{i}\right)=$ The index value of the $i$ dimension.

$\mathrm{P}_{\mathrm{ij}}=$ The weighted value of the AHP of the j-variable, the i dimension.

$\mathrm{I}\left(\mathrm{V}_{\mathrm{ij}}\right)=$ The index value of the jth variable, the i dimension. 
The SME in food competitiveness index is obtained by multiplying the value of the dimension index by the weighted value of the dimension. The formula used is:

$$
I D S=\sum_{i=1}^{n} P_{i} . I\left(D_{i}\right) \ldots \ldots \ldots(4)
$$

where :

$$
\begin{aligned}
& \text { IDS } \text { SME in food Index of } \\
& \text { competitiveness. } \\
& \mathrm{P}_{\mathrm{i}}= \\
& \\
& \mathrm{I}\left(\mathrm{D}_{\mathrm{i}}\right)=\text { The weighted value of AHP } \\
& \text { i-dimension. }
\end{aligned}
$$

\section{e. System Design}

The design of the system begins with the stage of mapping the process contained in the system in detail. Process mapping is done by creating data context diagrams and data flow diagrams. The next process is to create an entity relationship diagram to determine the relationship between the tables contained in the database. The coding process is done when both processes have been processed.

\section{f. System Testing}

System testing is done by assessing the performance of the system whether in accordance with the criteria or not, if not yet reached the criteria then it needed improvement in the coding process.

\section{RESULTS AND DISCUSSION}

\subsection{Home Page}

The home page showed by the program is a user login view. User should be login first to enter this system. The login view for the system user is shown in the Figure 1.
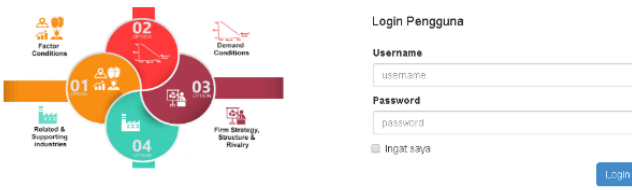

Figure 1. User system login view

Login Process need a username and a password which already registered, if the username and password are not registered, then the user will remain at the login page. For registering the username can be done by accessing the admin menu. The menu admin can add a new user for the system.

After the login process was completed, screen show the home page indicating that the user has successfully made the login process and is able to use this system. At the top right corner of the system view, there was a description of the username that is being used. To stop accessing the system, users can use the logout function located at the top right corner of the system view.

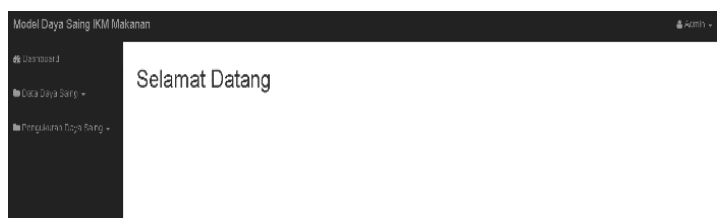

Figure 2. Home page of the user system

\subsection{Assessment Menu}

The assessment menu can be accessed by opening the competitiveness measurement menu which located on the left sidebar. Display ofassessment menu of SME show as the picture below, which also show the criteria for the assessment of competitiveness in SME.

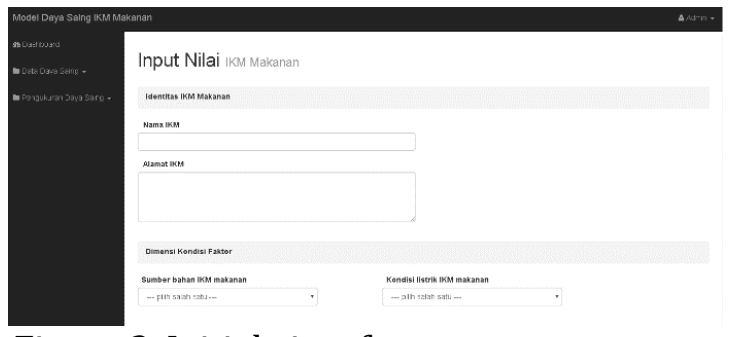

Figure 3. Initial view for assessment menu of SME in food

The user must fill the data in this menu. Firstly, user must fill the identity from the SME which will be measured. Secondly, user fill the criteria of competitiveness that adjusted to current condition. Lastly, the save button is available at the bottom right of the assessment menu. In addition to the save button there is a reset button that serves to delete all data that has been inputted in the criteria of competitiveness. 


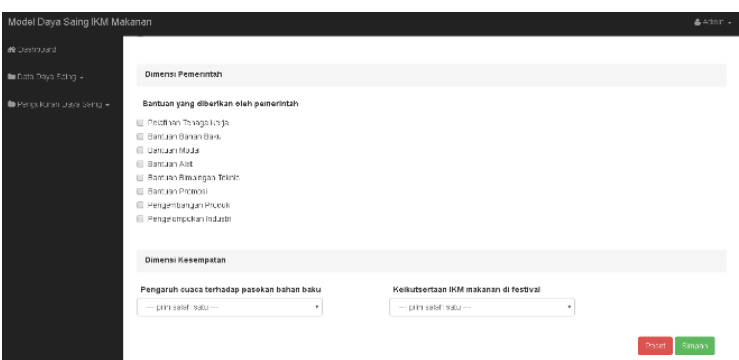

Figure 4. The final view for assessment menu of SME in food

After the user data is stored, user will be redirected to the data value of competitiveness to see the results of its assessment. To view the results of the assessment, the user must select the data based on the name of the SME in accordance with the name of the SME assessed in the previous process.

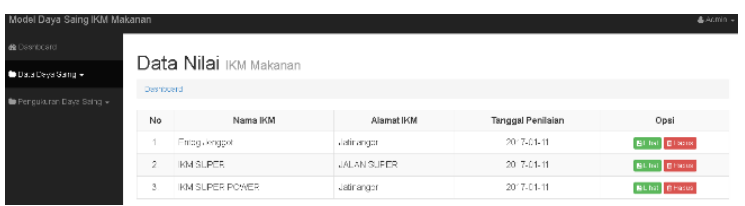

Figure 5. Table of results view for assessment menu of SME in food

Users will be given the choice whether they want to see the SME data or to delete it. There are two buttons, green button to see the assessment results and the red button to delete the assessment results.

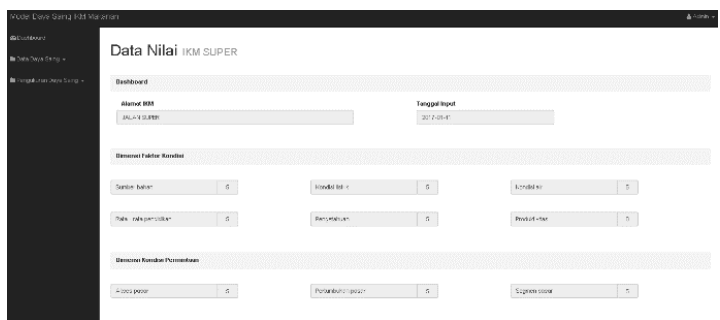

Figure 6. Data view for assessment menu of SME in food

Figure 6 is the results of the assessment of SME in food where there is the identity data of SME in food and the value of each indicators of competitiveness of it.

\subsection{Weighting Menu of Competitiveness}

The weighting menu of SME in food can be accessed by opening the competitiveness measurement menu on the left sidebar of the system page. The display of the weighting menu is shown on Figure 7.

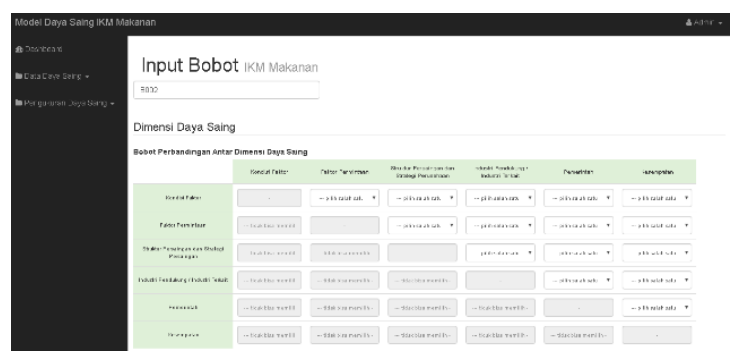

Figure 7. Weighting menu view of SME in food

Weighting processes divided into each appropriate level, to find the weighted value of each dimension then the value to be used is the value inputted in the competitiveness dimension table.

The weighting variables is divided according to the dimension occupied by the variable as in the hierarchy of competitiveness. The picture below is an example of a table view used to calculate the weighting variables.

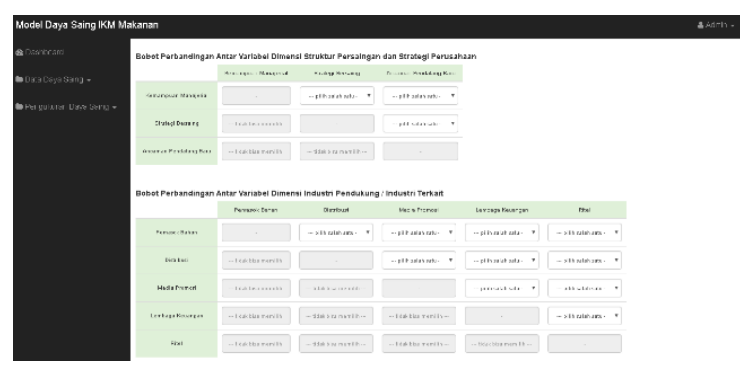

Figure 8. Weighting variables menu of SME in food

The weighting indicators table is similar to the weighting of the variables. The comparable indicator must be in the same variable and dimension. The picture below is an example of a view used to calculate the weighting indicator.

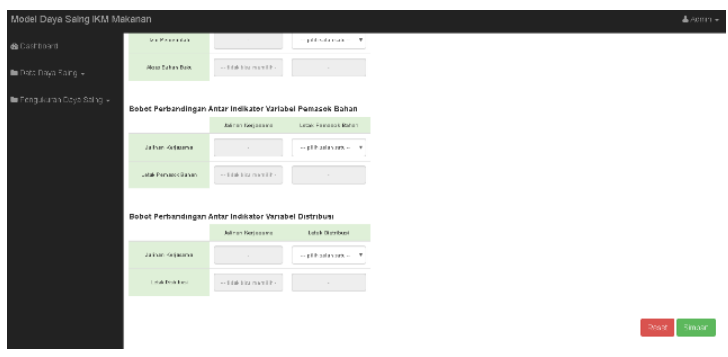

Figure 9. Weighting Indicator Menu for SME Competitiveness 
After all the data has been filled, users save the weighting data by clicking the green save button which reside in bottom corner in the weighting menu. The reset button is also included in the menu where the user wishes to delete the data that already stored in the table.

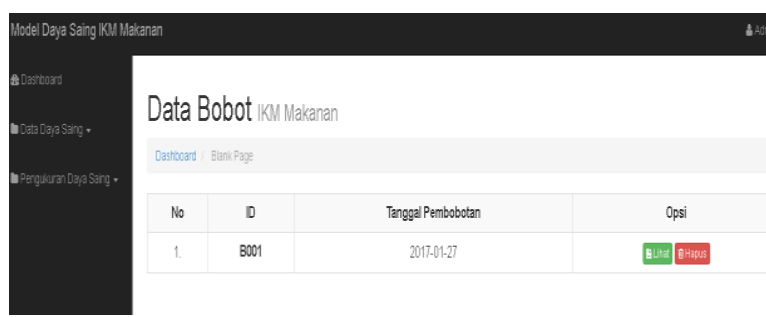

Figure 10. Table of weighting data of competitiveness

User will be redirected in the weighted data view after making the weighting process. Users will be given the choice whether to see the data or want to delete it. Two buttons are available: a green button to see the results and a red button to remove the results.

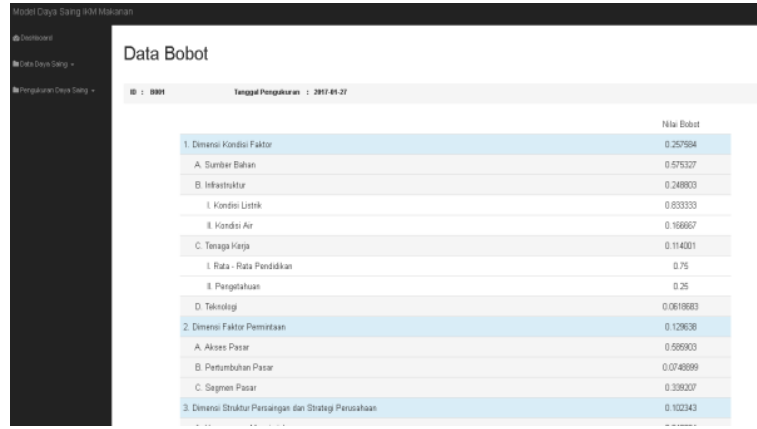

Figure 11. Details of weighting data of competitiveness

The display as shown above will appear when the user selects the view button on the weighting menu data page. The weighted data is a table where the weight value of each dimension is represented by a light blue background and below which there are variables and indicators in that dimension as in the hierarchy of competitiveness.

\subsection{Index Measurement Menu of SME in food}

Index measurement menu of SME in food can be accessed within the measurement of competitiveness menu. This menu is used to calculate the inputted index of SME in food.
Index of SME in food is gained from the early assessment which is conducted by respondent. The process that occurred in this menu require data on the value of SME in food and all data weighting data that have been inputted.

Views on this menu can be seen in the picture below. In this menu there is a table containing any SME which its index value could be calculated. In the options column there is a button that serves to run the process of calculating the index of SME in food.

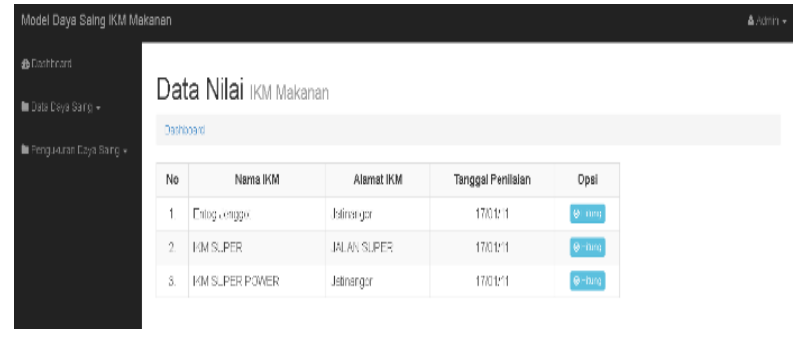

Figure 12. Menu view of index measurement of SME in food

Users will be directed to the index data page after calculating the index of one of the SME in food. On this page, table is shown that contain the name of SME, address and date of calculation index. The option field has two buttons, which is, a view button that serves to view the measurement results and the delete button to delete index data

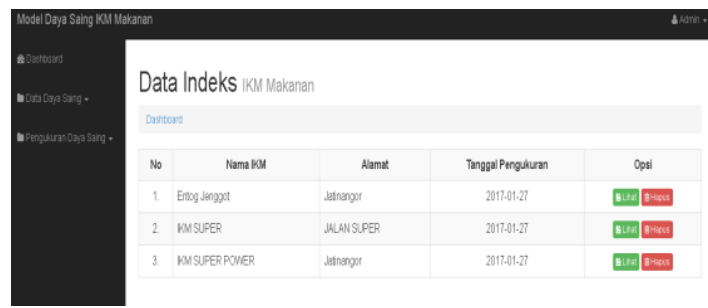

Figure 13. Table of results from index measurements of SME in food

The index's result data is a radar with six angles, which is the six dimensions of the diamond porter model. The value on the radar has a range of $0-1$, where 0 is the lowest index value and 1 is the highest index value. 


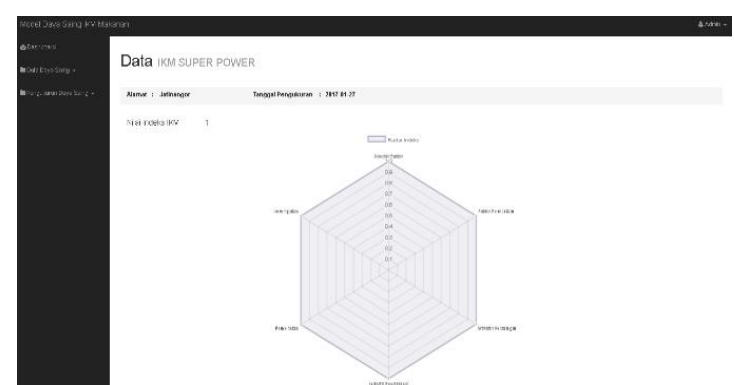

Figure 14. Radar display from dimensions of index measurements of SME in food

The table located on this page describes the value of the variables and the indicator which composed the dimensions. The index value in this table has the category level and color, where the details of the categories are listed in the table below:

Table 5. Category index value of competitiveness details

\begin{tabular}{ccc}
\hline Category & Detail & Information \\
\hline Level & Low & $0-0.33$ \\
\hline & Medium & $0.33-0.66$ \\
\hline & High & $0.66-1.00$ \\
\hline Color & & $0-0.20$ \\
\hline & & $0.20-0.40$ \\
\hline & & $0.40-0.60$ \\
\hline & & $0.60-0.80$ \\
\hline & & $0.80-1.00$ \\
\hline
\end{tabular}

\subsection{Index Measurement Menu of SME in City}

Index measurement of SME in City can be done after the index value of SME in City have been completed. The measurement of this index value combines the index value of the existing SME in one City.

This menu displays the index data of SME to be used in the measurement. Users can delete the data that they do not want to use in this measurement by using the red button.

If the data is complete, the user can use the button to calculate the city index. The use of the button will erase the value data and weighted data used in the index measurement.

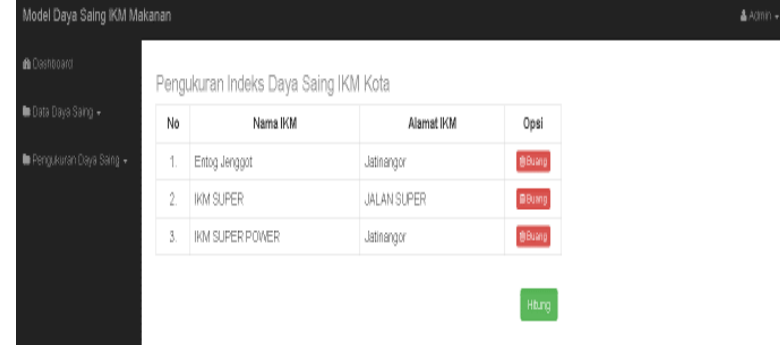

Figure 15. Menu view from city competitiveness index of SME.

The aims is to reload the index calculation data. Value data and weighted data are used only for once index measurement. Archived data will remain stored on the data value menu and weighting menu.

Users will be shown a radar that show the competitiveness of each dimension of SME in food in one city. In the view it will be listed the overall index value and the date of measurement as shown in the following figure.

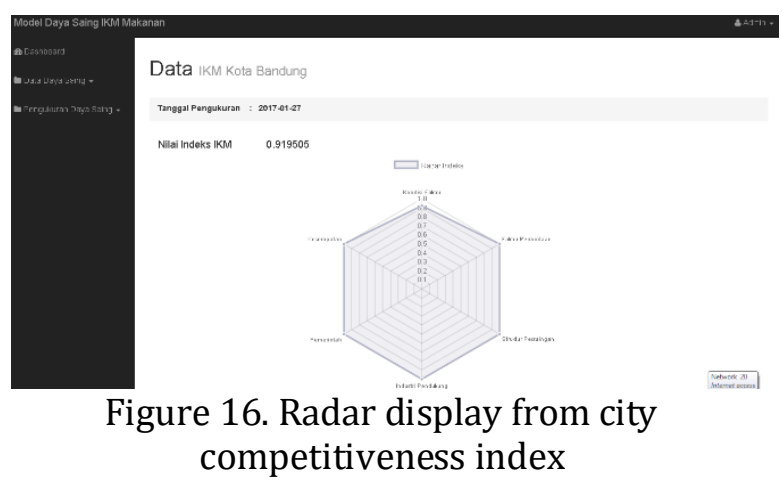

User can see the index value of SME in food details by scrolling to the data of City SME below. Those details explain index value from every dimension, variables, and indicators from competitiveness of SME in food.

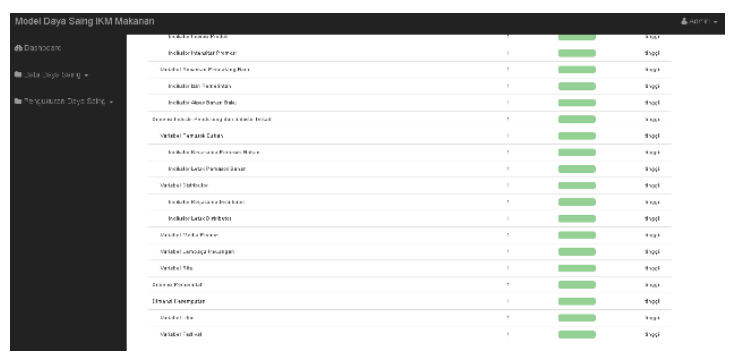

Figure 17. Details of city competitiveness index 


\subsection{Database System}

In measuring the competitiveness of SME in food there is a database that serve to store data measurement results. This system has one database which has one database there are several tables that have different functions. The functions of each table are described in the table below:

Table 6. Database System for SME in food Competitiveness Measurement

\begin{tabular}{|c|c|c|}
\hline $\begin{array}{l}\text { Databas } \\
\text { e }\end{array}$ & Table & Function \\
\hline \multirow[t]{9}{*}{$\begin{array}{l}\text { db_2804 } \\
1992\end{array}$} & abuser & $\begin{array}{l}\text { To store id and } \\
\text { password data of } \\
\text { the user. }\end{array}$ \\
\hline & tb_admin & $\begin{array}{l}\text { To store id and } \\
\text { password for admin }\end{array}$ \\
\hline & tb_nilai & $\begin{array}{l}\text { To store assessment } \\
\text { data of SME in food }\end{array}$ \\
\hline & $\begin{array}{l}\text { tb_indeks } \\
\text { _nilai }\end{array}$ & $\begin{array}{l}\text { To store assessment } \\
\text { data of SME in food } \\
\text { in one index } \\
\text { calculation }\end{array}$ \\
\hline & tb_bobot & $\begin{array}{l}\text { To store weighting } \\
\text { data from } \\
\text { respondent }\end{array}$ \\
\hline & $\begin{array}{l}\text { tb_indeks_b } \\
\text { obot }\end{array}$ & $\begin{array}{l}\text { To store weighting } \\
\text { data in one index } \\
\text { calculation. }\end{array}$ \\
\hline & $\begin{array}{l}\text { tb_indeks_ik } \\
\text { m }\end{array}$ & $\begin{array}{l}\text { To store the index } \\
\text { calculation results } \\
\text { of SME in food }\end{array}$ \\
\hline & tb_indeks & $\begin{array}{l}\text { To store data from } \\
\text { the index } \\
\text { calculation result of } \\
\text { SME in food which } \\
\text { will be used on ciy } \\
\text { competitiveness } \\
\text { index }\end{array}$ \\
\hline & $\begin{array}{l}\text { tb_indeks_k } \\
\text { ota }\end{array}$ & $\begin{array}{l}\text { To store the } \\
\text { calculation result of } \\
\text { city competitiveness } \\
\text { index }\end{array}$ \\
\hline
\end{tabular}

The above table is used in different views. The admin table (tb_admin) is used when the admin does the login process. The system will adjust the id and password that are inputted on the admin login page with the data contained in tb_admin.

User table (tb_user) is used when user logs the user or another user. The system will customize the user's id and password with the data contained in tb_user. Tb_user is also used on the first page after the admin login process. Tb_user is used to display user data when the admin wants to manage the system user account list.

The value table (tb_value) and value index table (tb_value) have the same function that is to store the data of the rating of SME in food by the user of the system. In the competitiveness menu, the system will display the value data from tb_nilai. tb_value is generated to store the result of continuous assessment while tb_index_value is used only temporarily. tb_index_ value is used in the index measurement menu of SME in food in competitiveness. After the process of measuring the competitiveness index of SME in food is done, the data contained in tb_index_values is automatically deleted.

The weighted table (tb_bobot) and weighted index table (tb_index_bobot) have roles similar to tb_value and tb_index_values. In the weighting menu, the data displayed by the system comes from tb_bobot. While tb_index_bobot is used when measuring the index of SME in food and the index measurements of competitiveness in city SME. Data in tb_index_bobot will be deleted after the process of index measurement of City SME.

The SME index table (tb_indeks_ikm) and the index table (tb_indeks) have the same function of storing the competitiveness data of SME in food. The data displayed on the menu of the index competitiveness data comes from tb_indeks_ikm. Tb_index is used by the system when the user will calculate the index competitiveness value of city SMU. Data on tb_index will be deleted after the calculation of city competitiveness index

The city competitiveness index is calculated by combining the index value of the SME in food that has been processed through the process of calculating the SME in food competitiveness index. The city competitiveness index will be stored by the system into the city index table (tb_indeks_kota). Data on tb_indeks_kota is used by the system to display data calculation of city competitiveness index.

\subsection{Admin System}

The admin system is used to manage user usernames. This menu has the function to change, delete or add a new username in this 
system. This menu can only be accessed using admin username, to enter into this menu admin must first do the login process.

The admin system provides some buttons with different functions. Edit button serves to change user username and password who already registered. Delete button serves to clear user username and password if it is not used anymore. To add new username and password it will be on the right side of the users table. Input the new username and password and click the add button. New data will be added in the left table

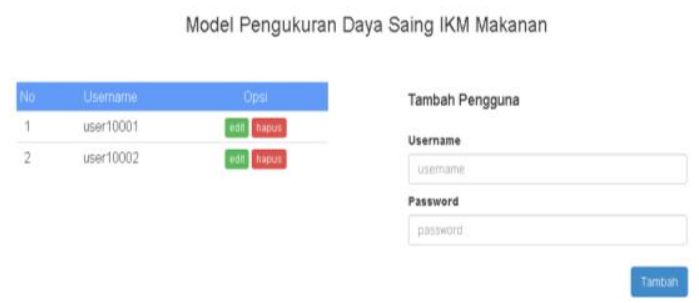

Figure 18. View for managing user account system

\subsection{System Evaluation}

The system has been tested several times with trial data. The results obtained in accordance with the simulations that have been conducted manually. This system still lacks in some parts. Weighting by using AHP can show consistency from data taken from the respondent, weighting used in this system can not be determined consistency.

This system has not been able to provide recommendations for SME actors and government for the next steps in improving the competitiveness of SME. The system can only display the conditions of competitiveness of SME in foods with low, medium and high category.

System view changes cannot be performed in the system admin menu. Display changes should be made using the coding process. It is still the lack of this system.

\subsection{Black Box Testing}

Black box testing on this system aims to examine the function of each part of the system.

\section{a. User system login page.}

The system will bring up a warning if one of the fields has not been filled or a username does not match with the password in the database. Disadvantages in the login page include:

- Username field can be filled with anything

- There is no character restriction on the username field

\section{b. Assessment of competitiveness in SME in food page.}

On this page the function of the system is running correctly. The reset button will clear back the filled data and the save button will save the assessment data to the database. The system will alert the user if there are unfilled fields.

\section{c. Weighting of competitiveness in SME in food page.}

On this page, all functions of the button are already running properly. The reset button will empty the filled form, while the save button will store the weighting data into the database. Weighting data ID and weighting data date will be auto-filled by the system.

\section{d. Assessment data / Weighting data of SME in food}

On this page each button is working properly. The view button will display the data in the database according to the selected SME's name. The delete button serves to delete existing data in the database according to the name of the SME selected by the user. The system will send a message to re-verify by the user before the selected data want to be deleted.

\section{e. Index measurement of SME in food page}

On this page there is only one button that serves to calculate the index value of SME in food. This button is working properly and if clicked the system will alert the user to verify again before system start calculating.

f. Index measurement of City SME page. 
On this page there are two buttons which is delete and calculate. The delete button serves to delete the index data of SME in food that user does not want to use. The system will provide a message to re-verify before the data is deleted. However, this button is not working properly, there is still an error in the program that causes the delete button not working properly. The calculate button serves to process the calculation of the index of SME in food based on the index data contained in the list. This button is working correctly where the system will process the data in the list to become one with information on the index of SME in food.

\section{CONCLUSION}

According to the research in this study, conclusions that can be concluded are:

1. The competitiveness of SME in food is specified by six dimensions of diamond porter model which are:

a) Condition factor dimensions; Consists of 4 variables (resources, infrastructure, labor and technology) and 4 indicators (electrical condition, water condition, average education and knowledge).

b) Condition of demand dimensions; Consists of 3 variables (access to market, market growth, and market segment) and 3 indicators (marketing area, marketing condition, market target).

c) Competition Structure and Corporate strategy dimensions; Consists of 3 variables (managerial ability, competitive strategy and newcomer threats) and 7 indicators (work hour distribution, the structure of company, product innovation, intensity of promotion, product standardization, access to raw materials, government permission).

d) Supporting industry dimensions; Consists of 5 variables (materials supplier, distributors, promotion media, financial institution and retail) and 2 indicators (cooperation and industry location).

e) Governmental dimensions; Consists of 1 variable that contain about government's help to SME in food. f) Dimension of Opportunity

g) Consists of 2 variables (climates and festival) and 2 indicators (climate condition and festival participation).

2. The competitiveness measurement system of SME in food that has been designed is able to display index data of SME with the detail of index value of each dimension, variable and indicator that affect on competitiveness where index value is categorized in low, medium and high level.

\section{REFERENCES}

[1] Asmara, A. Y. (2013). Meningkatkan Daya Saing Industri Kecil Menengah Melalui Inovasi dan Pemanfaatan Jaringan Sosial: Pembelajaran Dari Klaster Industri Software Di India.

[2] Porter, M. E. (1990). Competitive Strategy. New York, United States: The Free Press.

[3] Saaty, T.L. (1983). Axiomatic Foundations of the Analytic Hierarchy Process, Management Science.

[4] The World Bank. (2012). Laporan Perbandingan Kebijakan Usaha di Indonesia. The World Bank and International Finance Corporation.

[5] Wiyadi. (2005). Pengukuran Indeks Daya Saing IKM Di Jawa Tengah. Siasat Bisnis, 77-92. 